Article

\title{
Laccase-Based Biosensor Encapsulated in a Galactomannan-Chitosan Composite for the Evaluation of Phenolic Compounds
}

\author{
Imane Boubezari ${ }^{1,2}$, François Bessueille ${ }^{2}$, Anne Bonhomme ${ }^{2}$, Gaëtan Raimondi ${ }^{2}$, \\ Ali Zazoua ${ }^{1}\left(\mathbb{D}\right.$, Abdelhamid Errachid ${ }^{2}$ and Nicole Jaffrezic-Renault ${ }^{2, * \mathbb{D}}$ \\ 1 Laboratory of Applied Energetics and Materials, University of Jijel, Ouled Aissa 18000, Algeria; \\ boubezari.imen@gmail.com (I.B.); azazoua@yahoo.fr (A.Z.) \\ 2 Institute of Analytical Sciences, University of Lyon, 69100 Villeurbanne, France; \\ francois.bessueille@univ-lyon1.fr (F.B.); anne.bonhomme@isa-lyon.fr (A.B.); \\ gaetan.raimondi@isa-lyon.fr (G.R.); abdelhamid.errachid-el-salhi@univ-lyon1.fr (A.E.) \\ * Correspondence: nicole.jaffrezic@univ-lyon1.fr; Tel.: +33-437423516
}

Received: 25 May 2020; Accepted: 19 June 2020; Published: 22 June 2020

\begin{abstract}
Galactomannan, a neutral polysaccharide, was extracted from carob seeds and characterized. It was used for the first time for the fabrication of a laccase-based biosensor by the encapsulation of laccase in a chitosan+galactomannan composite. The fabricated biosensor was characterized by FTIR, scanning electron microscopy and cyclic voltammetry. The pyrocatechol detection was obtained by cyclic voltammetry measurements, through the detection of o-quinone at $-0.447 \mathrm{~V}$. The laccase activity was well preserved in the chitosan+galactomannan composite and the sensitivity of detection of pyrocatechol in the $10^{-16} \mathrm{M}-10^{-4} \mathrm{M}$ range was very high. The voltammetric response of the biosensor was stable for more than two weeks. To estimate the antioxidant capacity of olive oil samples, it was shown that the obtained laccase-based biosensor is a valuable alternative to the colorimetric Folin-Ciocalteu method.
\end{abstract}

Keywords: galactomannan; chitosan; laccase; voltammetry; phenolic content

\section{Introduction}

Galactomannans are linear polysaccharides based on a -(1-4)-mannane backbone to which single D-galactopyranosyl residues are attached via -(1-6) linkages. They can be extracted from different seeds (carob [1] and Trigonella foenum-graceum [2]). Their molecular composition depends on their origin, in particular the galactose content and the mannose/galactose ratio. The molecular size and the fine structure (mannose/galactose ratio and galactose distribution in the mannose linear chain) influence solubility, ability to self-associate and control the rheological properties of their aqueous solutions. Galactomannans are industrially used in many domains: paper, textile, pharmaceutical, cosmetic and in food products as E410 additive (ice cream and other preparations). The main important property of this biopolymer is its ability to form a very viscous solution at relatively low concentration, to stabilize dispersion and emulsion and to replace fat in many dairy products. In this paper galactomannan was extracted from carob seeds. Galactomannan was used in interpenetrating polymeric network with chitosan [3] and in polyvinyl alcohol [4] for the encapsulation of drugs in nanoparticles and their control release. This polysaccharide was used for the encapsulation of enzymes in delivery systems of antimicrobial peptides and enzymes (protease and lipase), their own activity being well preserved [5].

Due to their antioxidant character, phenolic compounds, secondary plant metabolites, have been attracting the attention of scientists in recent years. They can also protect against many human diseases such as cancer or cardiovascular disease [6]. For these reasons, an important effort has been made to 
characterize the phenol content in plant tissues [7]. The highly sensitive methods such as GC/MS or HPLC/MS are expensive, time consuming and need a pretreatment step of the sample. Electrochemical biosensors [8], based on the immobilization of an enzyme such as laccase or tyrosinase, constitute an excellent alternative.

Several laccase-based biosensors were fabricated through the encapsulation of laccase in chitosan including nanomaterials or chitosan+carrageenan, as presented in Table 1.

Table 1. Comparison of the analytical performance for previously published laccase biosensors using chitosan as immobilization matrix.

\begin{tabular}{|c|c|c|c|c|}
\hline Laccase Immobilization Matrix & $\begin{array}{c}\text { Linear Range } \\
(\mu \mathrm{M})\end{array}$ & $\begin{array}{l}\text { LOD } \\
(\mu \mathrm{M})\end{array}$ & $\begin{array}{l}\text { Shelf life Time } \\
\text { (Days) }\end{array}$ & References \\
\hline Laccase/MWCT/chitosan & $0.091-12.1$ & 0.233 & - & [9] \\
\hline $\begin{array}{l}\text { LBL assemblies of chitosan/ionic } \\
\text { liquid/phthalocyanine }\end{array}$ & $2.4-26$ & $8.96 \times 10^{-4}$ & - & [10] \\
\hline $\begin{array}{c}\text { Copper } \\
\text { nanoparticles/chitosan/multiwalled } \\
\text { carbon nanotubes/polyaniline-Au }\end{array}$ & $1-500$ & 0.156 & 10 & {$[11]$} \\
\hline Graphene/Chitosan Composite Film & $2-100$ & 0.26 & 10 & [12] \\
\hline $\begin{array}{c}\text { Chitosan/Fe } \mathrm{Fe}_{3} \mathrm{O}_{4} \text { nanoparticles/reduced } \\
\text { graphene oxide }\end{array}$ & $6 \times 10^{-3}-0.228$ & $18 \times 10^{-3}$ & 60 & [13] \\
\hline Chitosan/AuNPs/Phthalocyanine & $2.4-20$ & $8.55 \times 10^{-4}$ & - & [14] \\
\hline on $\mathrm{Fe}_{3} \mathrm{O}_{4} /$ polyaniline/laccase/chitosan & $0.5-80$ & 0.4 & 60 & [15] \\
\hline chitosan modified with trymiristine & $10^{-14}-10^{-9}$ & $10^{-14}$ & 60 & [16] \\
\hline Chitosan- Lambda-Carrageenan & $10^{-14}-10^{-8}$ & $3 \times 10^{-15}$ & 60 & [17] \\
\hline Graphene oxide -glycerol-chitosan & $0.2-15$ & $76 \times 10^{-3}$ & 15 & [18] \\
\hline Chitosan/Galactomannan & $10^{-10}-100$ & $10^{-10}$ & 15 & This work \\
\hline
\end{tabular}

The advantages for the encapsulation of an enzyme such as laccase in a polysaccharide (chitosan) are that its activity is preserved and some interferences are canceled. The integration of nanomaterials in chitosan increases the sensitivity of detection. It was demonstrated that the use of a chitosan-carrageenan complex for the encapsulation of an enzyme such as glucose oxidase increases the sensitivity of the voltammetric detection of glucose [19].

In this work, a galactomannan/chitosan (CHIT) polymer composite was used for the encapsulation of the enzyme laccase in a voltammetric biosensor because it was previously shown that galactomannan was able to preserve enzyme activity and this property has never applied to date to a biosensor design. The enzyme/polymer composite was deposited on a thiol modified gold electrode and then cross-linked in a glutaraldehyde vapor, through the formation of imide links between glutaraldehyde and the amine groups of chitosan. The detection of catechol was obtained through the voltammetric detection of the 1,2-benzohydroquione, product of the enzymatic reaction. The analytical performance of the fabricated laccase-based biosensor was determined for catechol detection. The phenolic content of olive oil was tested on diluted olive oil samples, without any further preparation procedure. The phenolic content of olive oil (main compound: hydroxytyrosol) confers to this product antioxidant, cardioprotective, ROS scavenging and anticancer properties [20]. A comparison of olive oils from different origins was operated with the fabricated laccase-based voltammetric biosensor and with a common colorimetric test.

\section{Materials and Methods}

\subsection{Reagents}

Sulfuric acid, ethanol, isopropanol, acetone, acetic acid,4-aminothiophenol (4-ATP, 97\%), chitosan (CHIT; average MW $=45 \mathrm{kDa}$ with a degree of acetylation $>75.0 \%$ ), glutaraldehyde (GA), pyrocatechol $(\geq 99 \%$ ), laccase (Enzyme Commission number $(\mathrm{EC})=1.10 .3 .2$, from Trametes versicolor, 85 0.94 U/mg), Folin and Ciocalteu's phenol reagent $(2 \mathrm{M})$ and sodium carbonate were purchased from Sigma-Aldrich. 
Aqueous solutions were prepared using Milli Q water (resistivity $18.2 \mathrm{M} \Omega \cdot \mathrm{cm}$ ). Phosphate buffer solution, PBS $(0.1 \mathrm{M})$, was prepared from monopotassium and dipotassium phosphate salts, sodium and potassium chlorides and adjusted to $\mathrm{pH} 7$.

\subsection{Extraction of Galactomannan from Carob Seeds (Ceratonia Siliqua)}

The experimental procedures were as follows [1]:

Carob seeds are composed of hull, endosperm and germ. They were separated from cloves, using pincers.

The hull was manually separated from the endosperm after heating the carob seeds in a sulfuric solution $\left(\mathrm{H}_{2} \mathrm{SO}_{4} / \mathrm{H}_{2} \mathrm{O} 60 / 40 \mathrm{v} / \mathrm{v}\right)$, at $60{ }^{\circ} \mathrm{C}$ for $1 \mathrm{~h}$. This treatment carbonizes the hull. The germs were then manually separated by splitting lengthwise the endosperm, after soaking in water for one night. In order to obtain the raw carob gum (locust bean gum (LBG)), the endosperms were washed, dried and grinded. The LBG was dissolved in hot water $\left(80^{\circ} \mathrm{C}\right)$ for one night. The solution was then centrifuged and the supernatant was recovered. After addition of isopropanol at $40^{\circ} \mathrm{C}$, centrifugation, the base was recovered as the white gum that contains galactomannan (GAL). From the raw carob gum, the recovery rate was $13 \%$.

\subsection{Analytical Characterization of LAC/CHIT + GAL}

FTIR spectra were recorded on the galactomannan film and on the laccase/galactomannan+chitosan film drop-coated on the gold electrode, by using a Nicolet Continuum microscope coupled with Nexus infrared spectroscopy in the specular reflectance mode, equipped with an MCT detector. The resolution used for measurements was equal to $4 \mathrm{~cm}^{-1}$ and the signal was processed through Happgenzel apodization.

The average molar masses of galactomannan dissolved in water $(1 \%(\mathrm{w} / \mathrm{w})$ was determined by SEC chromatography, using an Agilent Technologies system [16].

Scanning electron microscopy (SEM) images were realized on the galactomannan film and on the laccase/galactomannan+chitosan film drop-coated on the gold electrode, by using a VEGA TESCAN SEM.

Cyclic voltammetry (CV) measurements were carried out at room temperature using a Bio-Logic SPS analyzer instrument (Bio-Logic, France). Data processing was realized via EC LAB software. A $5 \mathrm{~mL}$ three electrode cell equipped with a platinum plate as a counter electrode, an $\mathrm{Ag} / \mathrm{AgCl}$ electrode as a reference one and a modified gold plate as a working electrode was used. For the electrochemical characterization of the modified gold electrode, the $\mathrm{CV}$ measurements were performed in $10 \mathrm{mM}\left[\mathrm{Fe}\left[(\mathrm{CN})_{6}\right]^{3-/ 4-}\right.$ in PBS $(0.1 \mathrm{M}, \mathrm{pH} 7)$, at a scan rate of $80 \mathrm{mV} / \mathrm{s}$. For the determination of the analytical performance of the biosensor, the $\mathrm{CV}$ measurements were performed in presence of different concentrations of pyrocatechol in PBS solution $(0.1 \mathrm{M}, \mathrm{pH} 7)$, at a scan rate of $80 \mathrm{mV} / \mathrm{s}$.

\subsection{Preparation of the Laccase Modified Gold Electrode}

The gold substrates (300 nm of gold layer/30 nm of titanium layer/300 nm SiO2/p-type Si/300 nm $\mathrm{SiO}_{2}$ ) were supplied by the French RENATECH Network (LAAS, CNRS Toulouse, France). The surface of the electrode was cleaned in acetone for $5 \mathrm{~min}$, then in UP water and finally incubated in a piranha solution $\left(\mathrm{H}_{2} \mathrm{SO}_{4}: \mathrm{H}_{2} \mathrm{O}_{2}=3: 1 \mathrm{v} / \mathrm{v}\right)$, then cleaned in UP water with drying under nitrogen flow. The schematic illustration the fabrication of the LAC/CHIT+GAL film on the gold electrode is presented in Figure 1.

Step 1: formation of the 4-ATP self-assembled monolayer; Step 2: formation of laccase/chitosan+galactomannan mixture; Step 3: Drop-coating of the laccase/galactomannan+chitosan film on the gold electrode and Step 4: Cross-linking in the glutaraldehyde vapor for $20 \mathrm{~min}$. 


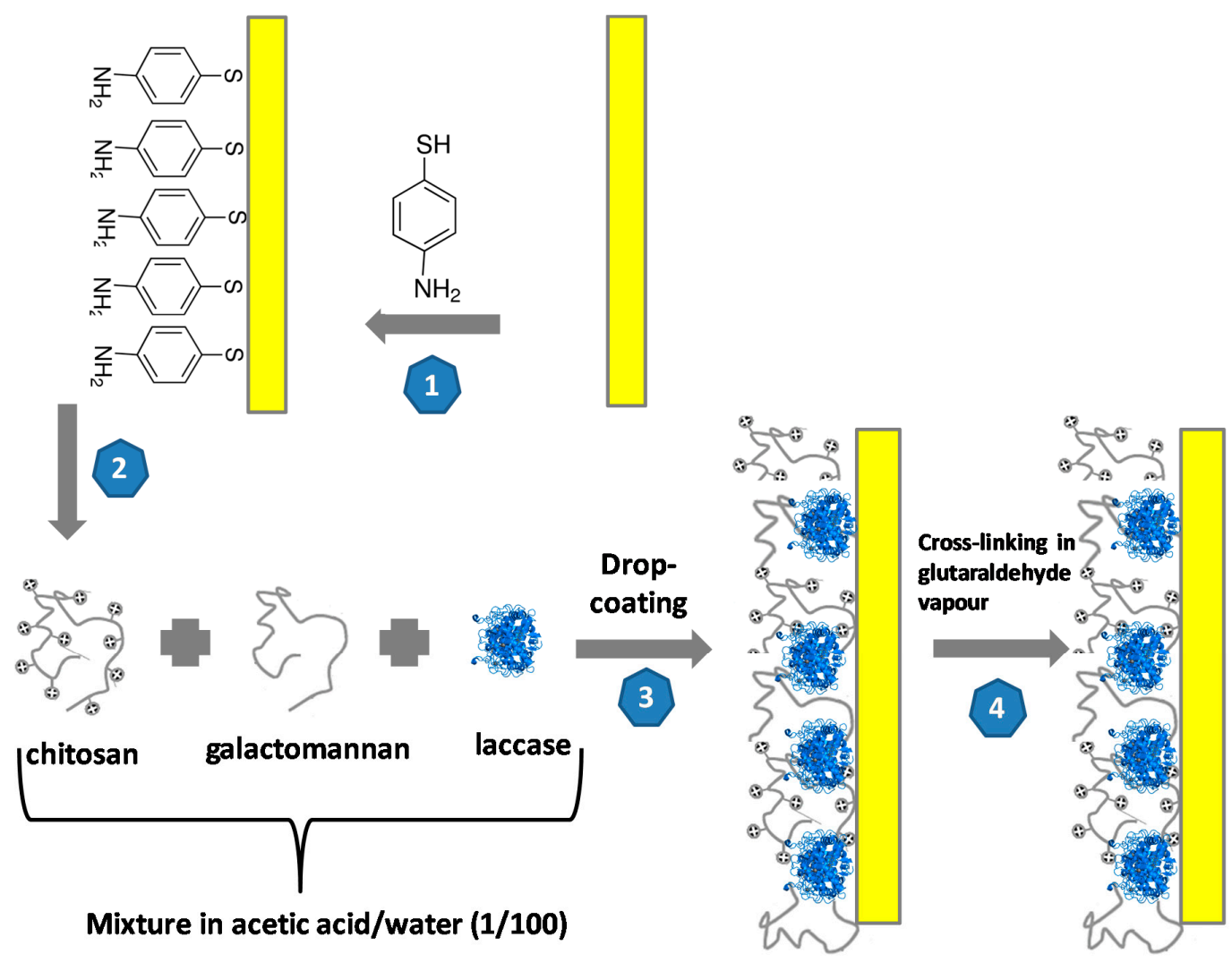

Figure 1. Schematic illustration the fabrication of the LAC/CHIT+GAL film on the gold electrode.

The cleaned electrodes were incubated in $0.1 \mathrm{M}$ ethanolic solution of 4-ATP for $12 \mathrm{~h}$ to form an anchored self-assembled monolayer (SAM) on the electrode surface. The electrode was then rinsed with ethanol.

A gel solution was prepared by mixing $0.5 \mathrm{~mL}$ of $\mathrm{S} 1$ solution and $0.5 \mathrm{~mL}$ of $\mathrm{S} 2$ solution:

- $\quad$ S1: $10 \mathrm{mg}$ of chitosan dissolved in $0.1 \mathrm{~mL}$ of acetic acid $+4.9 \mathrm{~mL}$ of water after $24 \mathrm{~h}$.

- S2: $10 \mathrm{mg}$ of galactomannan dissolved in $5 \mathrm{~mL}$ of hot water $\left(45^{\circ} \mathrm{C}\right)$ after $5 \mathrm{~h}$.

Ten milligrams of laccase was mixed in the gel solution. Ten microliters of this laccase/ chitosan+galactomannan mixture was deposited on the 4-ATP/gold electrode surface. Then this surface was exposed to a glutaraldehyde vapor for an optimized duration time $20 \mathrm{~min}$. The glutaraldehyde vapor was generated in a closed vessel, above a $25 \%$ glutaraldehyde solution in water, at ambient temperature. This vapor contained glutaraldehyde monomers that crosslinked amino groups from chitosan and from 4-ATP by forming imine groups, therefore this step insured the anchoring of the cross-linked laccase/chitosan+galactomannan film on the gold electrode and decreased the hydration rate of the film. Then LAC/CHIT+GAL modified gold electrode was kept at $4{ }^{\circ} \mathrm{C}$ for $24 \mathrm{~h}$.

\subsection{Application of the Biosensor for Detection of Phenolic Content in Olive Oil Samples}

Olive oils obtained from different origins (Tunisia, Algeria, Morocco and Spain) were tested. Olive oils consist of mixtures refined olive oils and of virgin olive oils. Samples were stored in the dark at room temperature and opened just before use to prevent the oxidative degradation of the samples. Under optimized conditions, $5 \mathrm{~mL}$ of hexane standards or oil samples $(1 \mathrm{~g})$ diluted to $5 \mathrm{~mL}$ with hexane were placed in test tubes. Then, $100 \mu \mathrm{L}$ of aqueous $1 \mathrm{M} \mathrm{HCl}$ solution were added and the mixture was shaken for 2 min using vortex agitation. Next, phases were separated by centrifugation for $10 \mathrm{~min}$ at $4000 \mathrm{rpm}$. The upper organic phase was carefully removed with a glass pipette and the remaining acidic aqueous phase (i.e., $40 \mu \mathrm{L}$ ) was retrieved with a syringe for final analysis. Cyclic 
voltammetric measurements were conducted in this extract, after dilution in PBS $0.1 \mathrm{M}, \mathrm{pH} 7$ for the electrochemical detection of phenolic content. A colorimetric test was conducted in this extract by using the Folin-Ciocalteu reagent for comparative purposes. The Folin-Ciocalteu reagent was composed of a mixture of phosphotungstic acid $\mathrm{H}_{3} \mathrm{PW}_{12} \mathrm{O}_{40}$ and of phosphomolybdic acid $\mathrm{H}_{3} \mathrm{PMo}_{12} \mathrm{O}_{40}$ that are able to oxidize the phenolic compounds and then become reduced, leading to an increase of the absorption at $765 \mathrm{~nm}$ [21]. Forty microliters of the extract was mixed with $200 \mu \mathrm{L}$ of the Folin-Ciocalteu reagent and $800 \mu \mathrm{L}$ of $7.5 \% \mathrm{Na}_{2} \mathrm{CO}_{3}$ solution, diluted up to $4 \mathrm{~mL}$ and incubated for $2 \mathrm{~h}$ in the dark before spectrophotometric determination; the absorbance was measured at $765 \mathrm{~nm}$. The calibration curve was constructed using caffeic acid aqueous standards from 0 to $300 \mathrm{mg} / \mathrm{L}(N=5)$ in $1 \mathrm{M} \mathrm{HCl}$.

\section{Results and Discussion}

\subsection{Characterization of the Prepared Galactomannan}

The FTIR spectrum of galactomannan is shown in Figure 2a. As they were previously identified [4], the characteristics absorption bands of galactomannan are present: the absorption band at $1651 \mathrm{~cm}^{-1}$ is of the ketonic carbonyl group. GAL showed characteristic peaks at $3376 \mathrm{~cm}^{-1}$ for O-H stretching of hydroxyl group and near about $2917 \mathrm{~cm}^{-1}$ For CH2 bending/wagging. A broad peak at $1029 \mathrm{~cm}^{-1}$ represented $\mathrm{C}-\mathrm{O}-\mathrm{H}$ stretching.

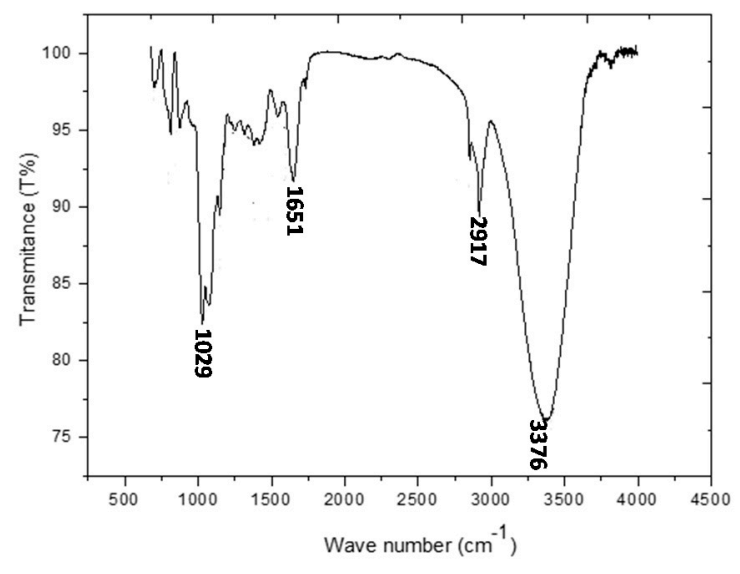

(a)

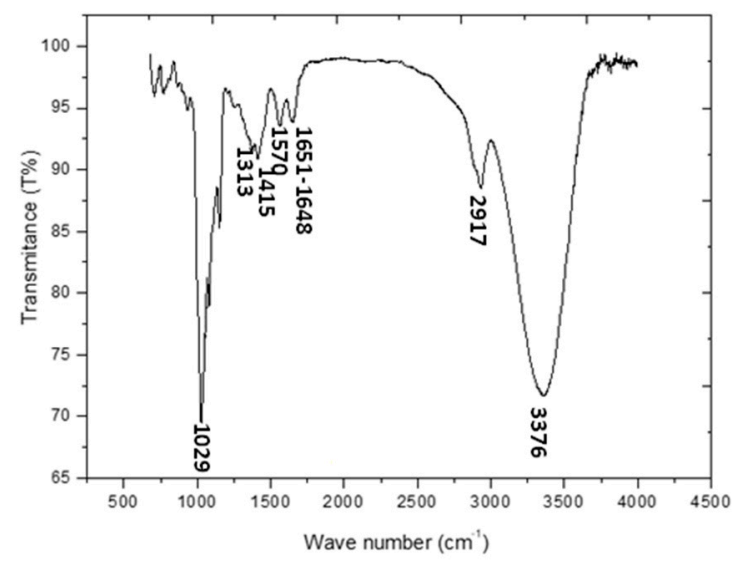

(b)

Figure 2. (a) FTIR spectrum of the prepared galactomannan and (b) FTIR spectra of the prepared laccase/galactomannan+chitosan film. 
The molecular weight of galactomannan is found to be $850 \mathrm{kDa}$ with a polydispersity index of 1.57. This value is close to that found for galactomannan extracted after acidic treatment of the carob seeds [1]. In this type of GAL, the mannose/galactose ratio was found to be 3.6, according to the molecular unit presented in Figure S1. This type of polysaccharide presents a non-ionic character [3], then it can be easily incorporated in a positively charge polymer such as chitosan. The global charge of this composite is then positive. The laccase whose isoelectric point is 3.6 [22] is negatively charged at pH 5-6 and can be tightly encapsulated in this positively charged composite.

\subsection{Characterization of the Gold Electrode Modified with the Laccase/Chitosan+Galactomannan Film}

- Spectroscopic characterization

FTIR spectrum of the prepared laccase/galactomannan+chitosan film is presented in Figure $2 \mathrm{~b}$. The main peaks of galactomannan $\left(1651 \mathrm{~cm}^{-1}, 3376 \mathrm{~cm}^{-1}, 2917 \mathrm{~cm}^{-1}\right.$ and $\left.1029 \mathrm{~cm}^{-1}\right)$ and of chitosan $\left(1415 \mathrm{~cm}^{-1}\right.$ and $\left.1313 \mathrm{~cm}^{-1}\right)$ are reported. The presence of the encapsulated laccase in the chitosan+galactomannan film was evidenced by the occurrence of two absorption bands at $1570 \mathrm{~cm}^{-1}$ and $1648 \mathrm{~cm}^{-1}$ characteristics of respectively amide I and amide II of laccase [23].

- Microscopic characterization

SEM images of the galactomannan+chitosan film without and with encapsulated laccase are presented respectively in Figure 3a,b. Galactomannan+chitosan film presents some cracks whereas the encapsulation of the hydrophilic laccase brings a more homogenous film with a globular structure.

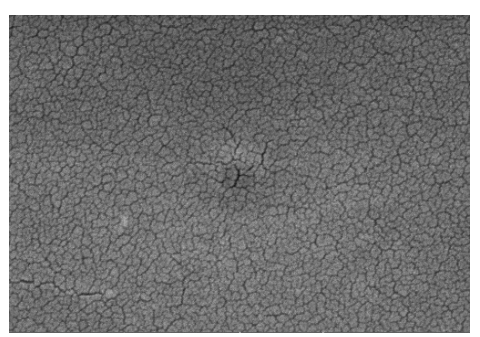

(a)

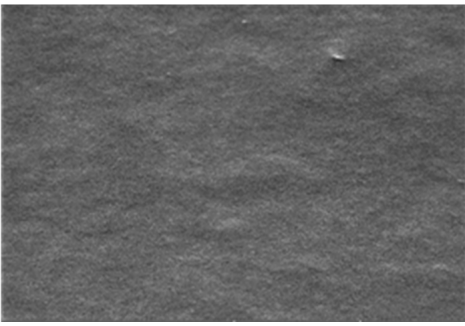

(b)

Figure 3. SEM images of the chitosan+galactomannan film without (a) and with the encapsulated laccase (b).

- Electrochemical characterization

Cyclic voltammetric method, in the presence of the redox probe $\left[\mathrm{Fe}(\mathrm{CN})_{6}\right]^{3-/ 4-}$, allows the study of the charge transfer at the modified electrode/electrolyte interface. The cyclic voltammograms obtained during the successive steps for the preparation of the modification of the gold electrode are presented in Figure 4.

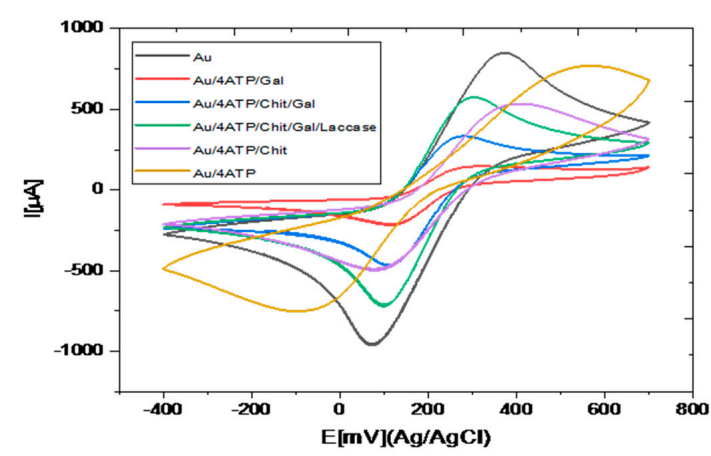

Figure 4. Cyclic voltammograms obtained for $\mathrm{Au}, \mathrm{Au} / 4-\mathrm{ATP}, \mathrm{Au} / 4-\mathrm{ATP} / \mathrm{CHIT}, \mathrm{Au} / 4-\mathrm{ATP} / \mathrm{GAL}$, $\mathrm{Au} / 4-\mathrm{ATP} / \mathrm{CHIT} / \mathrm{GAL}$ and Au/4-ATP/Chit/GAL/Laccase: $10 \mathrm{mM}\left[\mathrm{Fe}\left[(\mathrm{CN})_{6}\right]^{3-/ 4-}\right.$ in PBS (0.1 M, pH 7). 
Table S1 reported redox peak maximum intensities (Ia and Ic) and Ep and for the different steps of the modification of the gold electrode. A large increase of Ep is observed after the thiol SAM formation on the gold electrode surface. The high viscosity of the galactomannan film led to a large decrease of the peak maximum intensities; the insertion of galactomannan in chitosan led to a large increase of the peak maximum intensities by a factor higher than 2 , showing the improvement of the charge transfer due to the presence of chitosan. This point shows the interest of using a galactomannan = chitosan composite rather than pure galactomannan for the electrochemical detection. After encapsulation of laccase, the peak maximum intensities are doubled, due to the presence of copper in the active site of the enzyme [24].

\subsection{Analytical Performance of the Biosensor}

Laccase catalyzes the oxidation of pyrocatechol to 1,2-benzoquinone according to the following equation:

$$
\text { catechol }+\mathrm{O}_{2} \stackrel{\text { Laccase }}{\rightarrow} \text { o-quinone }+\mathrm{H}_{2} \mathrm{O}
$$

o-quinone can be then electrochemically reduced to pyrocatechol at the surface of the proposed biosensor, as indicated by the electrochemical reaction:

$$
\text { o-quinone }+2 \mathrm{H}^{+}+2 \mathrm{e}^{-} \rightarrow \text { catechol }
$$

In Figure 5a, cyclic voltammograms of the laccase/CHIT+GAL modified gold electrode in the presence of pyrocatechol are presented. The reduction peak corresponding to the reduction of o-quinone appeared at $-447 \mathrm{mV}$ for concentrations of pyrocatechol of $10^{-16} \mathrm{M}$. When concentrations of pyrocatechol increased, the potential of the reduction peak was shifted towards positive potentials until $-380 \mathrm{mV}$ for a pyrocatechol concentration of $10^{-4} \mathrm{M}$. The value of this cathodic potential was very low compared to that observed when laccase was encapsulated in chitosan + Carrageenan (-1.35 V) [16]. This point shows that the charge transfer was easier in CHIT+GAL film.

The intensity of the cathodic peak increased when the concentration of pyrocatechol increased. The variation of the intensity of the cathodic peak maximum was reported versus the concentration of pyrocatechol concentration, in the range $10^{-16}-10^{-4} \mathrm{M}$ in Figure 5a A linear relation was observed between the I (intensity for a concentration of pyrocatechol-intensity without catechol) and logarithm of the pyrocatechol concentration, in the range $10^{-16}-10^{-4} \mathrm{M}$. The slope of the straight line was $\mathrm{S}=1.58 \mu \mathrm{A}$, with a correlation coefficient $\mathrm{R}^{2}$ of 0.99 . The detection limit was calculated from the equation: Limit of Detection (LOD) $=3 \sigma / S$, where $\sigma$ is the background for the blank. It is found to be $10^{-16} \mathrm{M}$. The relative standard deviation for three biosensors was 3.5\%. The obtained detection limit was in the low range of those of the previously published laccase-based biosensors fabricated through the encapsulation of laccase in chitosan, as presented in Table 1 [9-18].

The repeatability of the biosensor was tested, the measurements were performed after storage of the biosensor at $4{ }^{\circ} \mathrm{C}$. The relative standard deviation found after 15 days was $5 \%$, showing the good preservation of the laccase in the chitosan+galactomannan composite.

\subsection{Application of the Biosensor for the Compared Estimation of Phenolic Content in Olive Oils Samples}

The cyclic voltammograms obtained in the extracts of olive oil samples diluted in 0.1 M PBS solution are presented in Figure 6. The cathodic peak potentials were in the same range as those obtained for the detection of catechol in 0.1 M PBS (Figure 5a).

A graphic comparison of the results obtained by the laccase-based biosensors and by the Folin-Ciocalteu method is shown in Figure 7. As can be observed, lower concentrations were systematically found with the biosensor compared to those obtained with the colorimetric method. This outcome could be explained considering the following: firstly, the Folin-Ciocalteu method estimates the total polyphenol content whereas the biosensor detects the concentration of pyrocatechol and other monophenols; moreover, the Folin-Ciocalteu reagent is considered a non-specific reagent by 
many authors since it can be reduced by non-phenolic compounds [25]. Thus, the Folin-Ciocalteu method could also reflect the presence of other oxidizable species present in the sample extract. Despite these differences, Figure 7 shows a high correlation between the results obtained by the two methods. The encapsulation of laccase in the chitosan+galactomannan composite prevents any inhibition effect of laccase by heavy metals and sulfhydryl compounds [26] that could be present in the olive oil samples. Accordingly, to estimate the antioxidant capacity of olive oil samples, we can conclude that the obtained laccase-based biosensor is a valuable alternative to the Folin-Ciocalteu method.

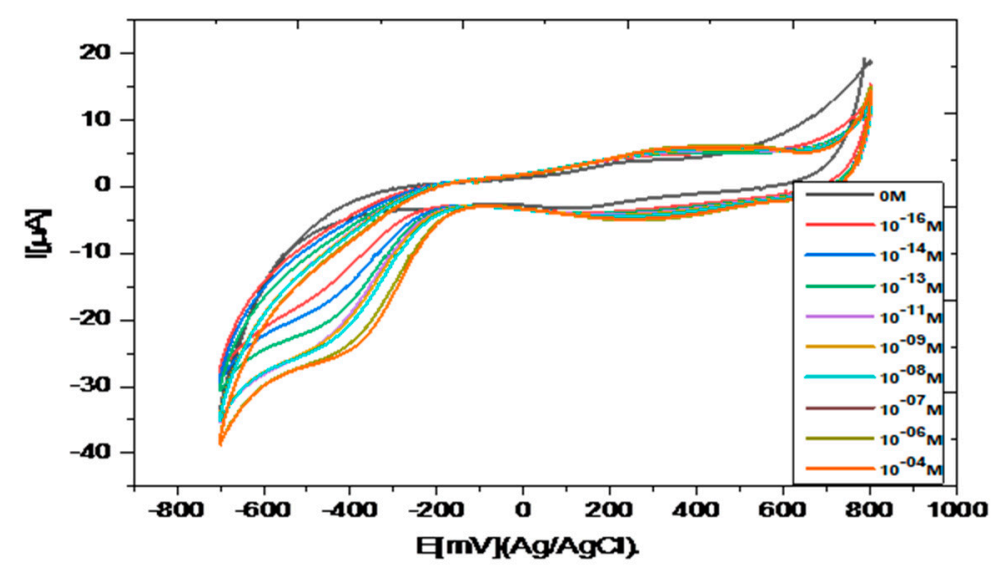

(a)

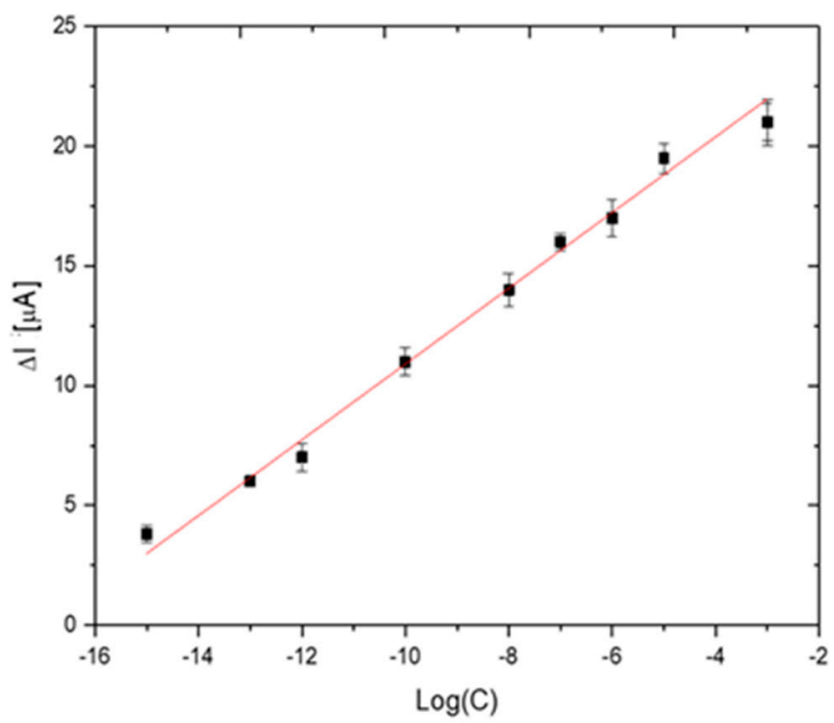

(b)

Figure 5. (a) Cyclic voltammograms observed for laccase/CHIT+GAL modified gold electrode in the presence of different concentrations of pyrocatechol. Scan rate of $80 \mathrm{mV} / \mathrm{s}$. PBS solution (0.1 M, pH 7); (b) calibration curve of the laccase-based biosensor: variation of the peak maximum intensity versus logarithm of concentration of pyrocatechol. 


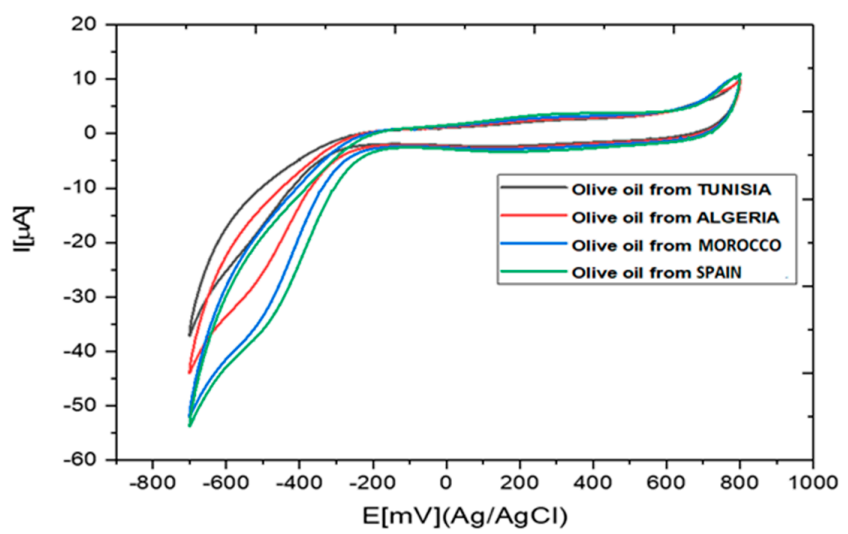

Figure 6. Cyclic voltammograms obtained in the presence of olive oil samples diluted in PBS (0.1 M, pH 7).

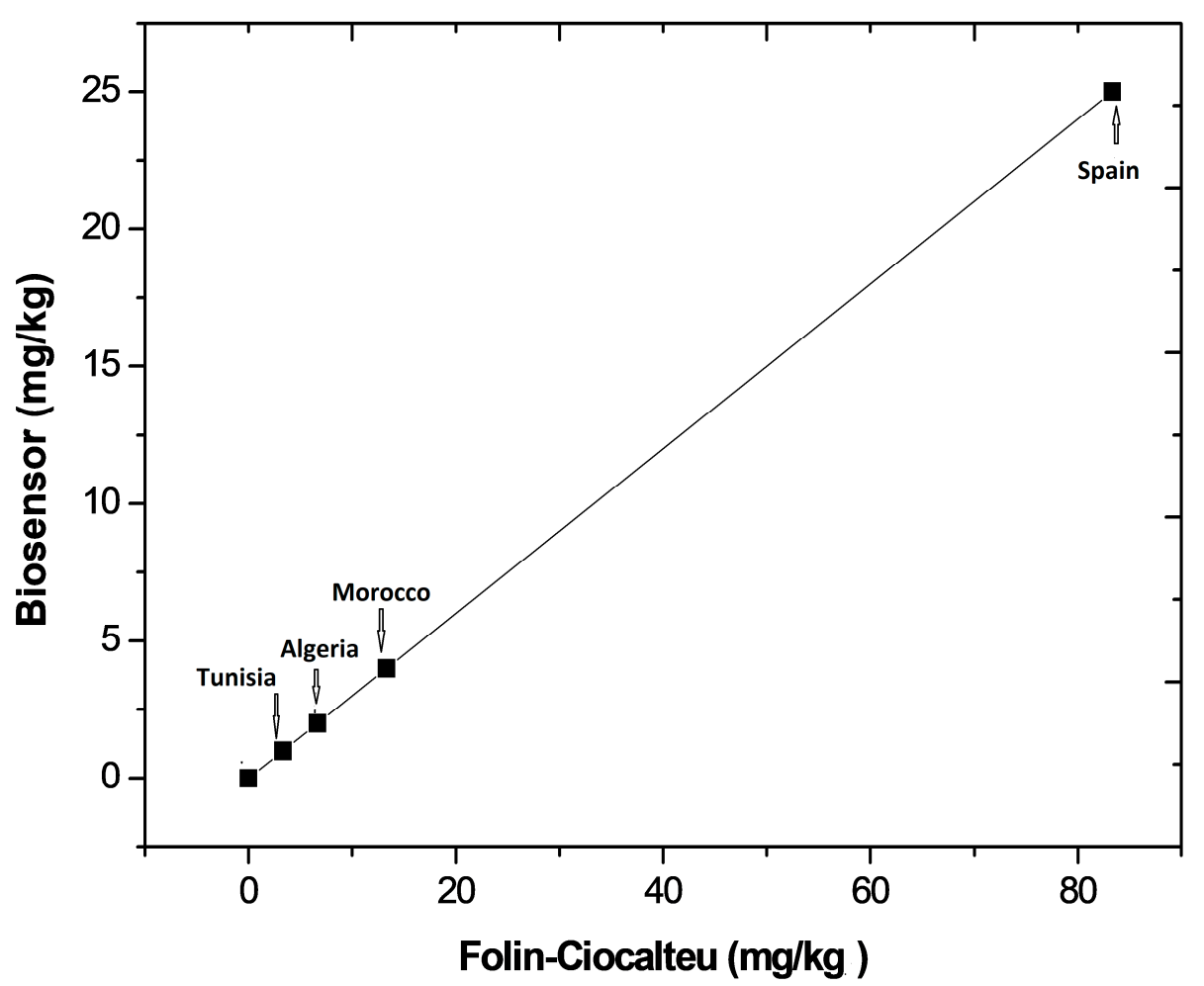

Figure 7. Graphical comparison of the results obtained with the laccase-based biosensor and with the Folin-Ciocalteu method.

\section{Conclusions}

Galactomannan was extracted from carob seeds and characterized. It was used for the first time for the fabrication of a laccase-based biosensor by the encapsulation of laccase in a chitosan+galactomannan composite. This composite is able to ensure a good charge transfer rate. The laccase activity was well preserved in this composite and the sensitivity of detection of pyrocatechol in the $10^{-16}-10^{-4} \mathrm{M}$ range, was very high. The voltammetric response of the biosensor was stable for more than two weeks. To estimate the antioxidant capacity of olive oil samples, it was shown that the obtained laccase-based biosensor is a valuable alternative to the colorimetric Folin-Ciocalteu method.

Supplementary Materials: The following are available online at http://www.mdpi.com/2079-6374/10/6/70/s1, Figure S1: Molecular unit of galactomannan, Table S1: Redox peak maximum intensities (Ia and Ic) and Ep and for the different steps of the modification of the gold electrode. 
Author Contributions: Methodology (F.B., A.B., G.R.); Investigation (I.B.); Resources (A.E.); Writing-original draft preparation (A.Z.); Writing-review and editing (N.J.-R.). All authors have read and agreed to the published version of the manuscript.

Funding: This research was funded by CAMPUS FRANCE, through PHC Maghreb \#39382RE.I. Boubezari thanks the government of Algeria for her work-study grant.

Conflicts of Interest: The authors declare no conflict of interest.

\section{References}

1. Dakia, P.; Blecker, C.; Robert, C.; Wathelet, B.; Paquot, M. Composition and physicochemical properties of locust bean gum extracted from whole seeds by acid or water dehulling pre-treatment. Food Hydrocoll. 2008, 22, 807-818. [CrossRef]

2. Leboukh, M.; Aouadi, S. Extraction and purification of galactmannans from Gleditsia triacanthos L. seeds. Alger. J. Arid Environ. 2017, 258, 1-6.

3. Jana, S.; Sen, K.K. Chitosan-Locust bean gum interpenetrating polymeric network nanocomposites for delivery of aceclofenac. Int. J. Biol. Macromol. 2017, 102, 878-884. [CrossRef] [PubMed]

4. Kaity, S.; Isaac, J.; Ghosh, A. Interpenetrating polymer network of locust bean gum-poly (vinyl alcohol) for controlled release drug delivery. Carbohydr. Polym. 2013, 94, 456-467. [CrossRef] [PubMed]

5. Campia, P.; Ponzini, E.; Rossi, B.; Farris, S.; Silvetti, T.; Merlini, L.; Brasca, M.; Grandori, R.; Galante, I.M. Aerogels of enzymatically oxidized galactomannans from leguminous plants: Versatile delivery systems of antimicrobial peptides and enzymes. Carbohydr. Polym. 2017, 158, 102-111. [CrossRef]

6. Lu, Y.; Yeap Foo, L. Polyphenolics of salvia-A review. Phytochemistry 2002, 59, 117-140. [CrossRef]

7. Pinelo, M.; Del Fabbro, P.D.; Manzocco, L.; Nunez, M.J.; Nicoli, M.C. Optimization of continuous phenol extraction from Vitis vinifera by products. Food Chem. 2005, 92, 109-117. [CrossRef]

8. Karim, F.; Fakhruddin, A. Recent advances in the development of biosensor for phenol: A review. Rev. Environ. Sci. Biotechnol. 2012, 11, 261-274. [CrossRef]

9. Diaconu, M.; Litescu, S.C.; Radu, G.L. Laccase-MWCNT-chitosan biosensor-A new tool for total polyphenolic content evaluation from in vitro cultivated plants. Sens. Actuators B Chem. 2010, 145, 800-806. [CrossRef]

10. Salvo-Comino, C.; Garcia-Hernandez, C.; Garcia-Cabezon, C.; Rodriguez-Mendez, M.L. Promoting laccase sensing activity for catechol detection using LBL assemblies of chitosan/ionic liquid/phthalocyanine as immobilization surfaces. Bioelectrochemistry 2020, 132, 107407. [CrossRef] [PubMed]

11. Chawla, S.; Rawal, R.; Pundir, C.S. Fabrication of polyphenol biosensor based on laccase immobilized on copper nanoparticles/chitosan/multiwalled carbon nanotubes/polyaniline-modified gold electrode. J. Biotechnol. 2011, 156, 39-45. [CrossRef]

12. Qu, J.; Lou, T.; Kang, S.; Du, X. Laccase biosensor based on graphene-chitosan composite film for determination of hydroquinone. Anal. Lett. 2014, 47, 1564-1578. [CrossRef]

13. Fernandes, P.M.; Campiña, J.M.; Silva, A.F. A layered nanocomposite of laccase, chitosan, and $\mathrm{Fe}_{3} \mathrm{O}_{4}$ nanoparticles-reduced graphene oxide for the nanomolar electrochemical detection of bisphenol A. Microchim. Acta 2020, 187, 1-10. [CrossRef] [PubMed]

14. Salvo-Comino, C.; González-Gil, A.; Rodriguez-Valentin, J.; Garcia-Hernandez, C.; Martin-Pedrosa, F.; Garcia-Cabezon, C.; Rodriguez-Mendez, M.L. Biosensors Platform Based on Chitosan/AuNPs/Phthalocyanine Composite Films for the Electrochemical Detection of Catechol. The Role of the Surface Structure. Sensors 2020, 20, 2152. [CrossRef] [PubMed]

15. Sadeghi, S.; Fooladi, E.; Malekaneh, M. A new amperometric biosensor based on $\mathrm{Fe}_{3} \mathrm{O}_{4}$ /polyaniline/laccase/chitosan biocomposite-modified carbon paste electrode for determination of catechol in tea leaves. Appl. Biochem. Biotechnol. 2015, 175, 1603-1616. [CrossRef]

16. Chakroun Galai, H.; Rassas, I.; Namour, P.; Bonhomme, A.; Raimondi, G.; Besbes Hentati, S.; Jaffrezic-Renault, N. A Laccase/Chitosan-Lambda-Carrageenan Based Voltammetric Biosensor for Phenolic Compound Detection. Electroanalysis 2020, 32, 732-740. [CrossRef]

17. Chakroun Galai, H.; Rahmouni, N.; Namour, P.; Bonhomme, A.; Bessueille, F.; Salma Besbes Hentati, S.; Jaffrezic-Renault, N. Highly Sensitive Voltammetric Catechol Biosensor Based on Electroaddressing of Laccase Encapsulated in Modified Chitosan. Sens. Lett. 2020, 18, 165-172. 
18. Boujakhrout, A.; Jimenez-Falcao, S.; Martinez-Ruiz, P.; Sanchez, A.; Diez, P.; Pingarron, J.M.; Villalonga, R. Novel reduced graphene oxide-glycol chitosan nanohybrid for the assembly of an amperometric enzyme biosensor for phenols. Analyst 2016, 141, 4162-4169. [CrossRef]

19. Rassas, I.; Braiek, M.; Bonhomme, A.; Bessueille, F.; Rafin, G.; Majdoub, H.; Jaffrezic-Renault, N. Voltammetric glucose biosensor based on glucose oxidase encapsulation in a chitosan-kappa-carrageenan polyelectrolyte complex. Mater. Sci. Eng. C 2019, 95, 152-159. [CrossRef]

20. Martínez, L.; Gaspar Ros, G.; Nieto, G. Hydroxytyrosol: Health Benefits and Use as Functional Ingredient in Meat. Medicines 2018, 5, 13. [CrossRef]

21. ISO14502-1: Determination of Substances Characteristic of Green and Black Tea-Part 1: Content of Total Polyphenols in Tea-Colorimetric Method Using Folin-Ciocalteu Reagent; AFNOR: Paris, France, 2005.

22. Hublik, G.; Schinner, F. Characterization and immobilization of the laccase from Pleurotus ostreatus and its use for the continuous elimination of phenolic pollutants. Enzyme Microb. Technol. 2000, 27, 330-336. [CrossRef]

23. Mei, Y.; Miller, L.; Gao, W.; Gross, R.A. Imaging the distribution and secondary structure of immobilized enzymes using infrared microspectroscopy. Biomacromolecules 2003, 4, 70-74. [CrossRef] [PubMed]

24. Zhu, Y.; Zhang, Y.; Zhan, J.; Lin, Y.; Yang, X. Axial bonds at the T1 Cu site of Thermus thermophilus SG0.5JP17-16 laccase influence enzymatic properties. FEBS Open Bio 2019, 9, 986-995. [CrossRef] [PubMed]

25. Fernández, E.; Vidal, L.; Canals, A. Rapid determination of hydrophilic phenols in olive oil by vortex-assisted reversed-phase dispersive liquid-liquid microextraction and screen-printed carbon electrodes. Talanta 2018, 181, 44-51. [CrossRef] [PubMed]

26. Baldrian, P. Fungal laccases occurrenceand properties. FEMS Microbiol. Rev. 2006, 30, 215-242. [CrossRef] [PubMed]

(C) 2020 by the authors. Licensee MDPI, Basel, Switzerland. This article is an open access article distributed under the terms and conditions of the Creative Commons Attribution (CC BY) license (http://creativecommons.org/licenses/by/4.0/). 